\title{
Estratégias de utilização de luz e estabilidade do desenvolvimento de plântulas de Cordia superba Cham. (Boraginaceae) crescidas em diferentes ambientes luminosos
}

\author{
Gustavo Maia Souza ${ }^{1,2}$, Bruno Depieri Balmant ${ }^{1}$, Hilton Fabrício Vítolo ${ }^{1}$, Karina Bornia Pedroso Gomes ${ }^{1}$, \\ Thiago Martins Florentino ${ }^{1}$, Tiago Aranda Catuchi ${ }^{1}$ e Willyam de Lima Vieira ${ }^{1}$
}

Recebido em 11/03/2008. Aceito em 17/09/2008

\begin{abstract}
RESUMO - (Estratégias de utilização de luz e estabilidade do desenvolvimento de plântulas de Cordia superba Cham. (Boraginaceae) crescidas em diferentes ambientes luminosos). A utilização fotossintética da luz é um componente fundamental para a distribuição das espécies ao longo de um gradiente de regeneração de clareiras. O trabalho teve como objetivo avaliar as estratégias de utilização da luz e como isto poderia afetar a estabilidade do desenvolvimento de plantas da espécie Cordia superba crescidas em dois ambientes com irradiações contrastantes. Para tanto, foi conduzido um experimento com plantas de 12 meses de idade de $C$. superba, uma espécie pioneira arbórea, crescidas a pleno sol e sombreamento de $85 \%$. Foram avaliados aspectos fisiológicos como crescimento e fluorescência da clorofila, e aspectos da arquitetura das copas como ângulo de folha e índice de área foliar. Também foi realizada uma análise da estabilidade do desenvolvimento por meio da avaliação da simetria foliar. Os resultados mostraram que esta espécie possui a capacidade de desenvolver diferentes fenótipos em resposta a disponibilidades de luz contrastantes, apresentando características de plantas de sol bem como de sombra nos respectivos ambientes de crescimento. Todavia, as plantas crescidas no ambiente ensolarado apresentaram folhas mais simétricas, em relação às plantas de sombra. Isto sugere que, apesar do ambiente de pleno sol possuir uma maior heterogeneidade ambiental do que ambientes sombreados, o status de espécie pioneira de $C$. superba parece ser uma característica adaptativa suficientemente desenvolvida para permitir a formação de um fenótipo estável em um ambiente variável
\end{abstract}

Palavras-chave: arquitetura de copa, fluorescência da clorofila, plasticidade fenotípica, simetria

\begin{abstract}
Light utilization strategies and developmental stability of Cordia superba Cham. (Boraginaceae) seedlings grown in different light environments). Photosynthetic light utilization plays a major role in species distribution along gap regeneration gradients. The aim of this study was to evaluate strategies of light utilization and the possible influence on developmental stability of seedlings of the woody pioneer species Cordia superba grown under contrasting light environments. To this end, an experiment was carried out with 12-month-old C. superba seedlings grown under full sunlight and under 85\% shade. Physiological aspects such as plant growth and chlorophyll fluorescence, and canopy architecture traits such as leaf angle and leaf area index were analyzed. A developmental stability analysis was also performed by leaf symmetry measurements. The results showed that $C$. superba seedlings have the capacity to develop different phenotypes in response to contrasting light availability, showing sun and shade plant traits according to respective growth environments. However, the plants grown in full sunlight showed more symmetric leaves than leaves developed in shade conditions. This suggests that, despite the greater environmental heterogeneity of full sunlight in relation to a shade environment, the status of pioneer species of $C$. superba seems to be a well developed adaptive trait allowing plants to develop a stable phenotype in a changing environment
\end{abstract}

Key words: canopy architecture, chlorophyll fluorescence, phenotypic plasticity, symmetry

\section{Introdução}

Em um ambiente natural, a luz é um dos fatores mais variáveis relacionados ao estabelecimento das plantas. Em um ambiente de clareira, a variação da irradiância depende, entre outros fatores, da posição do sol, altura das árvores que formam a borda da clareira e dinâmica da passagem de nuvens, apresentando uma faixa de 25 a $2.300 \mu \mathrm{mol}$ fótons $\mathrm{m}^{-2} \mathrm{~s}^{-1}$ que varia ao longo de um único dia, enquanto a irradiância em um subbosque é predominantemente baixa e difusa, com pontuações de feixes de luz direta através das copas das árvores (Bazzaz \& Picket 1980; Chazdon et al. 1996).

\footnotetext{
1 Universidade do Oeste Paulista, Laboratório de Ecofisiologia Vegetal, Rodovia Raposo Tavares, km 572, 19067-175 Presidente Prudente, SP, Brasil

2 Autor para correspondência: gustavo@unoeste.br
} 
De acordo com Pinheiro (1994), cerca de 55\% da energia solar não é usada na fotossíntese devido às perdas de luz por reflexão e transmissão para o solo. Dessa forma, o uso eficiente da luz pode ser uma característica fundamental para propiciar às plantas vantagem competitiva entre populações no que se refere ao maior aproveitamento da transformação de energia luminosa em energia química, tendo assim uma importante vantagem evolutiva.

Assim, a utilização fotossintética da luz é um componente fundamental para a distribuição das espécies ao longo de um gradiente de regeneração de clareiras, servindo como uma forma de se agrupar as espécies em grupos sucessionais. De forma geral, as espécies que demandam luz, possuem alta taxa de crescimento e altos valores de fotossíntese máxima são consideradas espécies pioneiras. Por outro lado, espécies tolerantes ao sombreamento com taxas fotossintéticas mais baixas são classificadas como espécies não pioneiras ou secundárias (Strauss-Debenedeti \& Bazzaz 1996). Nesse contexto, diversos estudos têm demonstrado variações morfo-estruturais em copas como forma de maximizar o uso da luz. Para Norman \& Campbell (1989), a arquitetura da vegetação afeta não somente as trocas de matéria e energia entre a planta e o ambiente, como também pode revelar a estratégia da planta para se ajustar aos processos evolutivos, como adaptações aos fatores físicos, químicos e biológicos. Segundo Hirose (2005), Boysen Jensen (1932) foi o primeiro autor a correlacionar a fotossíntese com a estrutura e disposição da copa, demonstrando a importância do arranjo das folhas no aproveitamento de luz. Posteriormente, Monsi \& Saeki (1953) quantificaram a interceptação da luz através da copa e modelaram a fotossíntese como uma integração dos processos fotossintéticos das folhas expostas a diferentes regimes de irradiância. Esses autores demonstraram que a estrutura da copa desenvolve-se de forma a maximizar a fotossíntese sobre um dado microclima de luz.

Segundo Loomis \& Williams (1969), Duncan (1971) e Barnes et al. (1990), atributos arquitetônicos em plantas, como por exemplo, o padrão de distribuição vertical do índice de área foliar (IAF) e a orientação dos limbos foliares influenciam significativamente a interceptação da irradiância e, conseqüentemente, o balanço de energia e as trocas gasosas entre planta e ambiente. A sobreposição de camadas de folhas submete a copa a diferentes intensidades de luz, sendo a primeira camada com maior irradiância incidente (Hirose 2005). A eficiência fotossintética líquida aumenta com o IAF, mas não indefinidamente, sendo limitada pelo autosombreamento que as folhas superiores exercem sobre as inferiores (Machado 1985). Na utilização de luz em baixa intensidade, o aumento da eficiência depende de um baixo grau de auto-sombreamento e da redução do ponto de compensação luminosa (Larcher 2004). Para Pickett \& Kempf (1980), o aumento da eficiência na interceptação de radiação luminosa em espécies tolerantes ao sombreamento está relacionado com um maior crescimento horizontal dos ramos, resultando em copas com baixos índices de densidade de área foliar e, portanto, baixo auto-sombreamento.

A anatomia da folha é altamente especializada para a absorção da luz, e as propriedades morfo-estruturais contrastantes entre os parênquimas paliçádico e lacunoso resultam numa absorção de luz mais uniforme através da folha (Taiz \& Zeiger 2004). De acordo com McCain et al. (1988), dentro de uma mesma copa, as folhas que estão sujeitas a diferentes regimes de luz apresentam diferenças anatômicas como, por exemplo, redução no comprimento das células do parênquima paliçádico, assim como na espessura do mesofilo nas folhas sombreadas.

Folhas de sombra possuem uma área foliar maior, baixo peso específico e menos cloroplastos se comparadas com as folhas de sol, devido à redução da espessura do mesofilo, com granas mais largas e maior quantidade de clorofila. As folhas de sol alcançam uma alta taxa fotossintética máxima, produzindo folhas mais espessas devido à formação de grandes células paliçádicas e/ou um aumento no número de camadas dessas células (Lambers et al. 1997).

Segundo Werner et al. (2001), a absorção de luz é mais alta em folhas posicionadas perpendicularmente aos raios solares. Folhas com orientação vertical reduzem a interceptação de luz excessiva, que é refletida devido à máxima eficiência fotoquímica do fotossistema II (FSII). O risco de fotoinibição é diminuído por causa da alta variação dos azimutes foliares, em conjunto com o azimute solar, diminuindo a quantidade de radiação total diária por folha, uma vez que, se uma folha está orientada para um determinado azimute, ela só receberá quantidade de luz fotoinibitória quando o sol estiver posicionado no mesmo azimute que ela. $\mathrm{O}$ posicionamento da folha em determinado ângulo também minimiza os efeitos da radiação excessiva (Larcher 2004). Danos fotoinibitórios são relatados como mudanças nas propriedades físicoquímicas das membranas do tilacóide e inatividade do transporte de elétrons. Esses fatores causam a redução no rendimento quântico do FSII, aumento da dissipação do excesso de energia não fotoquímica e diminuição da eficiência da carboxilação (Critchley 1998; Long et al. 1994). Freqüentemente, espécies arbóreas adaptadas ao sol apresentam menor eficiência quântica efetiva e potencial do FSII em relação às espécies de ambientes sombreados, e maiores taxas de transporte de elétrons e quenching não fotoquímico (Ribeiro et al. 2004; 2005). 
Portanto, a irradiância excessiva, que freqüentemente está associada a altas temperaturas e alta demanda atmosférica por vapor de água, pode levar a planta a uma condição de estresse. Segundo Larcher (2004), estresse é considerado um desvio significativo nas condições ótimas para a vida, e induz a mudanças e respostas em todos os níveis funcionais do organismo. Estresses ambientais causados por diversos fatores, entre eles a disponibilidade de luz, podem acarretar em um desenvolvimento anormal nos organismos. Por outro lado, sistemas biológicos possuem uma tendência inerente de buscar a manutenção de sua estabilidade, entendida como a capacidade do sistema manter sua organização e individualidade apesar das alterações morfofisiológicas estimuladas pelas variações ambientais (Souza \& Oliveira 2004).

A estabilidade do desenvolvimento é baseada na habilidade dos organismos em minimizar perturbações aleatórias durante seu desenvolvimento, enquanto a instabilidade desenvolvimental é freqüentemente usada como um meio de avaliar os efeitos daquelas perturbações ambientais nos organismos (Freeman et al. 1993; Graham et al. 1993; Møller \& Swaddlle 1997). Assim, estabilidade do desenvolvimento é a produção de um fenótipo pré-determinado por um design adaptativo, sob um dado grupo de condições ambientais e genéticas específicas. Um dos indicadores do desenvolvimento estável em plantas é a simetria. Uma incapacidade individual para conter distúrbios aleatórios durante o desenvolvimento de um organismo, sejam tais distúrbios de ordem genética ou ambiental, poderia ocasionar pequenos desvios na perfeita simetria do organismo ou em partes dele (Souza et al. 2004). Esses desvios são denominados de assimetria flutuante quando eles são não-direcionados e aleatórios (Palmer \& Strobeck 1986; Møller \& Swaddle 1997). Portanto, quanto mais simétrico um indivíduo, maior sua estabilidade desenvolvimental, sucesso reprodutivo e maior taxa de sobrevivência (Freeman et al. 1993).

Neste contexto, o objetivo deste estudo foi avaliar as estratégias de utilização da luz e como isto poderia afetar a estabilidade do desenvolvimento de plântulas da espécie Cordia superba Cham. (Boraginaceae) crescidas em dois ambientes com irradiações contrastantes. Neste estudo foram testadas as seguintes hipóteses: 1) a estabilidade do desenvolvimento das plântulas de C. superba crescidas em ambiente sombreado seria maior, uma vez que se trata de um ambiente que apresenta menor variabilidade ambiental e, conseqüentemente, menos perturbações; 2) as plântulas de $C$. superba crescidas no sol e na sombra mostram diferentes estratégias de utilização da luz como, por exemplo, maior teor de clorofila e eficiência fotoquímica nas plantas crescidas na sombra, enquanto sob plano sol as plantas desenvolvem maior auto-sombreamento e peso específico, embora com menor eficiência fotoquímica do fotossistema II (FSII).

\section{Materiais e métodos}

Local do estudo - O experimento foi conduzido em área experimental do Campus II da Universidade do Oeste Paulista (UNOESTE), localizada no oeste do Estado de São Paulo no município de Presidente Prudente ( $51^{\circ} 26^{\prime} 00^{\prime \prime}$ de Longitude Oeste de W.G e $22^{\circ} 07^{\prime} 30^{\prime \prime}$ de Latitude Sul) a uma altitude média de 433 metros. O clima da região é classificado como subtropical com temperatura e precipitação media anual de $23,1^{\circ} \mathrm{C}$ e $1.244 \mathrm{~mm}$, respectivamente; com verão quente e inverno com temperaturas moderadas e baixa precipitação (estação seca) (Setzer 1966).

Descrição da espécie - Cordia superba Cham. (Boraginaceae) é uma espécie arbórea esciófila e seletiva higrófila pouco freqüente ou quase rara. Habita as florestas úmidas, ocorrendo também em áreas abertas como espécie pioneira. Sua altura varia de 7 a $10 \mathrm{~m}$, com tronco de 20 a $30 \mathrm{~cm}$ de diâmetro. Folhas simples, ásperas ao tato na face inferior, com 18 a $24 \mathrm{~cm}$ de comprimento (Lorenzi 1992).

O presente estudo foi realizado com mudas de C. superba com aproximadamente 12 meses de idade adaptadas a diferentes intensidades luminosas: pleno sol e sombra. Sementes foram germinadas em vasos plásticos contendo $12 \mathrm{~kg}$ de solo tipo argissolo vermelhoamarelo de textura arenosa-média sob condições de 50\% de sombreamento e solo em capacidade de campo. Noventa dias após a germinação, as mudas foram transferidas para o local do experimento.

O delineamento experimental utilizado foi inteiramente casualizado, com dois tratamentos: pleno sol e sombreamento artificial limitando a luminosidade à cerca de $15 \%$ de irradiância com a utilização de sombrite preto. Foram utilizadas quatro repetições (plantas) por tratamento. As folhas sadias e totalmente expandidas de cada indivíduo foram identificadas com etiquetas e enumeradas em cada ramo individualmente.

Parâmetros avaliados - As medidas de fluorescência da clorofila $a$ foram realizadas com um fluorômetro portátil de luz modulada (modelo FMS-2, Hansatech, UK) em 16 folhas maduras, sadias e completamente expandidas por planta de cada tratamento de luz em diferentes orientações (Norte, Sul, Leste e Oeste) no horário das 11:00 às 15:00 h. Os parâmetros analisados foram: eficiência quântica potencial ( $\mathrm{Fv} / \mathrm{Fm})$ e efetiva $(\mu \mathrm{F} / \mathrm{Fm}$ ') do FSII, eficiência quântica da antena do FSII (Fv'/Fm'), 
quenching não-fotoquímico [NPQ $=($ Fm-Fm' $) / F m$ '] taxa de transporte de elétrons $(\mathrm{ETR}=\mathrm{DFFF} * \mu \mathrm{F} / \mathrm{Fm}$ ' $* 0,5 * 0,84$, onde DFFF é a densidade de fluxo de fótons fotossintéticos) (Bilger et al. 1995). Os valores de Fm e Fv indicam, respectivamente, as fluorescências máxima e variável, determinadas após 30 minutos de adaptação ao escuro, e Fm' a fluorescência máxima das plantas na presença de luz. As medidas de fluorescência foram realizadas sob irradiância média de $1530 \mu \mathrm{mol}$ fótons $\mathrm{m}^{-2} \mathrm{~s}^{-1}$ e temperatura de $37,4^{\circ} \mathrm{C}$ em ambiente aberto, enquanto a média de irradiância no ambiente sombreado foi de $134 \mu \mathrm{mol}$ fótons $\mathrm{m}^{-2} \mathrm{~s}^{-1} \mathrm{e}$ temperatura de $35,9^{\circ} \mathrm{C}$.

Para a obtenção do teor de clorofila nas folhas, utilizou-se um medidor portátil de clorofila (modelo CCM-200, OPTI-SCIENCE, USA), tomando-se sempre o cuidado de evitar a nervura central.

O número de folhas e ramos presentes nas plantas foi contado manualmente. As orientações cardeais (azimutes) das folhas e dos ramos foram obtidas com o auxilio de uma bússola, a qual tem como referencia o norte magnético, posicionada no ápice da folha. Os pontos cardeais considerados foram: norte, sul, leste, oeste, noroeste, nordeste, sudoeste e sudeste. Os valores de inclinação foliar foram coletados nas folhas etiquetadas pertencentes ao grupo de seleção previamente definido, com um transferidor com pêndulo centralizado considerando a inclinação em relação à vertical, sendo esta variável normalmente definida como sendo a inclinação do plano foliar em relação ao plano horizontal (Forseth \& Norman 1993).

O diâmetro do caule foi obtido medindo-se o colo do caule, com o auxílio de um paquímetro digital (Eletronic Digital Caliper, USA). A altura da planta foi determinada medindo-se o comprimento da parte aérea desde o nível do solo até o ápice da planta, e o comprimento dos ramos foi mensurado do extremo de um ramo até a sua inserção no caule principal com o ajuda de uma trena milimetrada.

Para a avaliação do peso específico foliar (relação entre a massa seca e a área da folha, $\mathrm{mg} \mathrm{cm}^{-2}$ ) foram selecionadas 4 folhas em cada repetição que estivessem completamente expandidas. Para a avaliação de área foliar $\left(\mathrm{cm}^{2}\right)$ foi utilizado um medidor portátil de área foliar (modelo LI-3000A, Li-Cor, USA). Na avaliação do peso $\operatorname{seco}(\mathrm{g})$, as folhas foram armazenadas em sacos de papel, identificadas e mantidas em estufa sob uma temperatura constante de $70{ }^{\circ} \mathrm{C}$ até obtenção de peso constante.

O índice de área foliar (IAF) foi calculado segundo Watson (1947) como a razão entre a área foliar total do dossel e a unidade da superfície projetada no solo. A superfície sombreada no solo foi estimada como a projeção circular da copa, considerando-se o diâmetro da circunferência como sendo o diâmetro médio da copa em cada indivíduo.

Para a avaliação da estabilidade do desenvolvimento das plantas em cada ambiente, as medidas de simetria em cada folha foram coletadas usando-se réguas rígidas milimetradas, medindo-se a largura dos lados esquerdo e direito, em relação à nervura central, nas porções basal (inserção do pecíolo), mediana e apical da folha. As medidas da porção basal foram feitas $2 \mathrm{~cm}$ acima da inserção do pecíolo na folha. O meio da folha foi determinado dividindo-se o comprimento total da folha por dois. A porção apical foi medida $2 \mathrm{~cm}$ acima do ápice da folha. Os desvios de simetria (d) foram calculados subtraindo-se as medidas do lado esquerdo do direito em cada porção da folha (A -A'; M-M'; B-B') conforme esquema a baixo (Fig. 1).

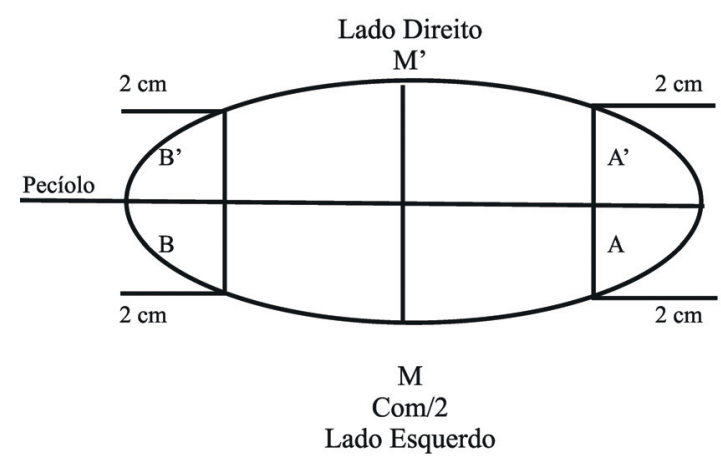

Figura 1. Esquema exemplificando a forma de coleta dos dados para o cálculo de simetria foliar nas plântulas de Cordia superba Cham. crescidas sob pleno sol e sombreamento artificial.

Os valores das medidas de simetria foram transformados em seus logaritmos para remover o efeito da escala de tamanho sobre os resultados. O desvio foi recalculado a partir destes novos valores $\left(\mathrm{d}=\log _{\mathrm{x}}-\log _{\mathrm{x}}{ }^{\prime}\right)$. Para normalizar os dados foi utilizada a transformação Box-Cox, $\mathrm{d}^{*}=\left(|\mathrm{d}|+0,00005^{0,33}\right)$ (Souza et al. 2005). No total, foram amostradas 162 folhas sadias e totalmente expandidas em cada ambiente. Os desvios entre cada ambiente foram comparados com teste $\mathrm{t}(\mathrm{p}=0,05)$. Para garantir que não houve simetria direcional (um lado específico estatisticamente maior que o outro), as medidas obtidas nos lados esquerdo e direito das folhas foram comparadas por teste $\mathrm{t}(\mathrm{p}=0,05)$.

Análise dos dados - O conjunto dos dados de fluorescência da clorofila $a$ foi submetido à análise de variância (ANOVA, p < 0,05) e as médias comparadas pelo teste Tukey, ao nível de 5\%, enquanto as médias dos dados de arquitetura de copa foram comparadas com teste de Tukey com $p=0,1$, uma vez que este tipo de dado normalmente apresenta uma variabilidade maior que dados obtidos a partir de medidas fisiológicas mais 
precisas (Souza et al. 2005). As análises foram realizadas com o programa estatístico Sisvar (Universidade Federal de Lavras).

\section{Resultados}

Em relação aos resultados da fluorescência da clorofila das folhas posicionadas em diferentes azimutes (norte, sul, leste, oeste) sob condições de pleno sol e sombreamento, o parâmetro de eficiência quântica potencial do FSII $(\mathrm{Fv} / \mathrm{Fm})$ foi significativamente $(\mathrm{p}<0,05)$ maior na sombra do que no sol. Dentro de
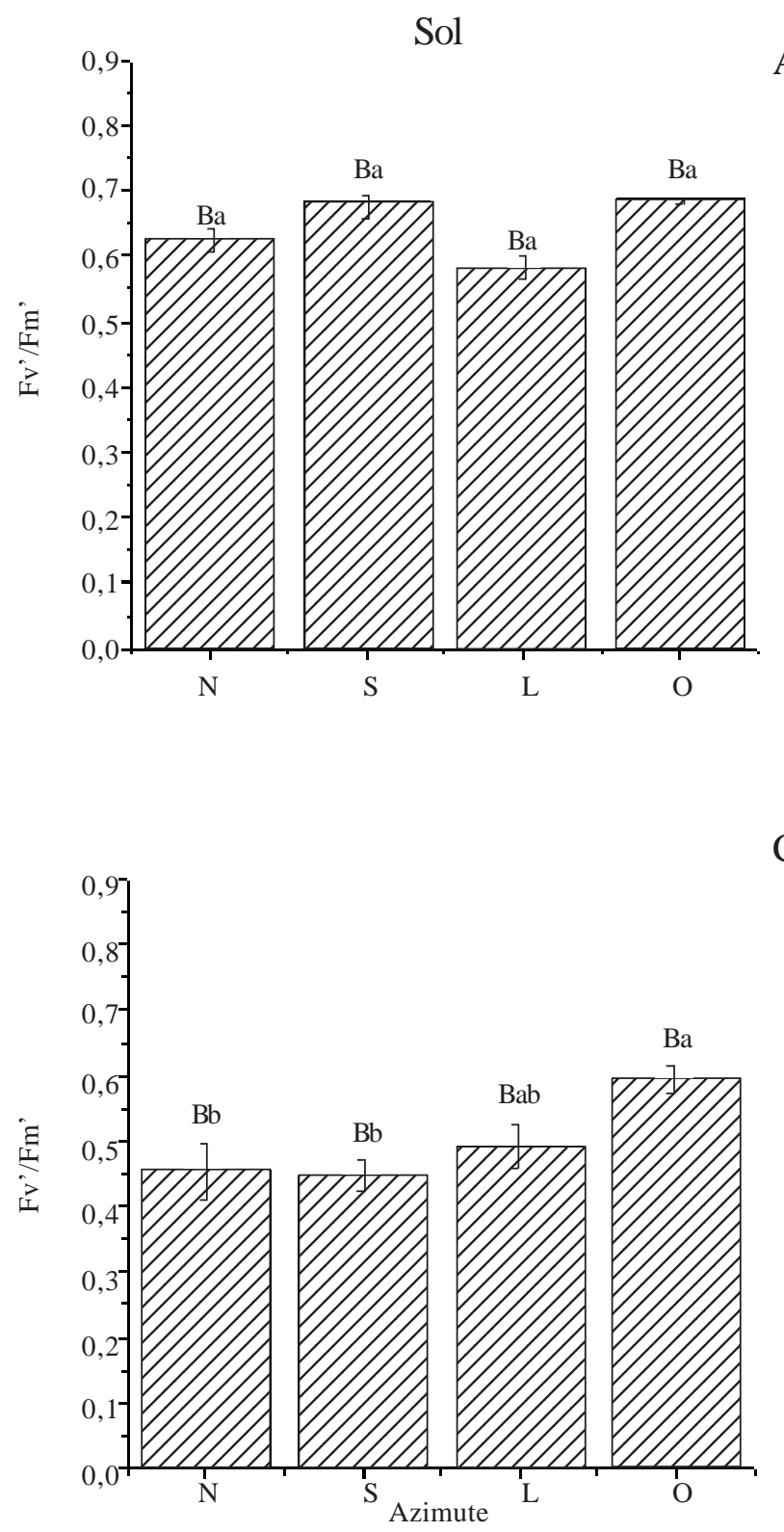

$\mathrm{C}$ cada ambiente, não houve diferença $(p>0,05)$ entre os azimutes (Fig. 2A-B). Em relação ao parâmetro de eficiência quântica da antena (Fv'/Fm'), os valores foram estatisticamente $(\mathrm{p}<0,05)$ maiores na sombra do que no sol. Em cada ambiente específico, enquanto as folhas das plantas na sombra não apresentaram diferenças $(p>0,05)$ consideráveis em relação aos diferentes azimutes, no ambiente ensolarado os valores de Fv'/Fm' no azimute oeste foram $(\mathrm{p}<0,05)$ maiores se comparados com o norte e o sul, as folhas no azimute leste não apresentaram diferenças significativas em relação aos azimutes norte, sul e oeste (Fig. 2C-D).
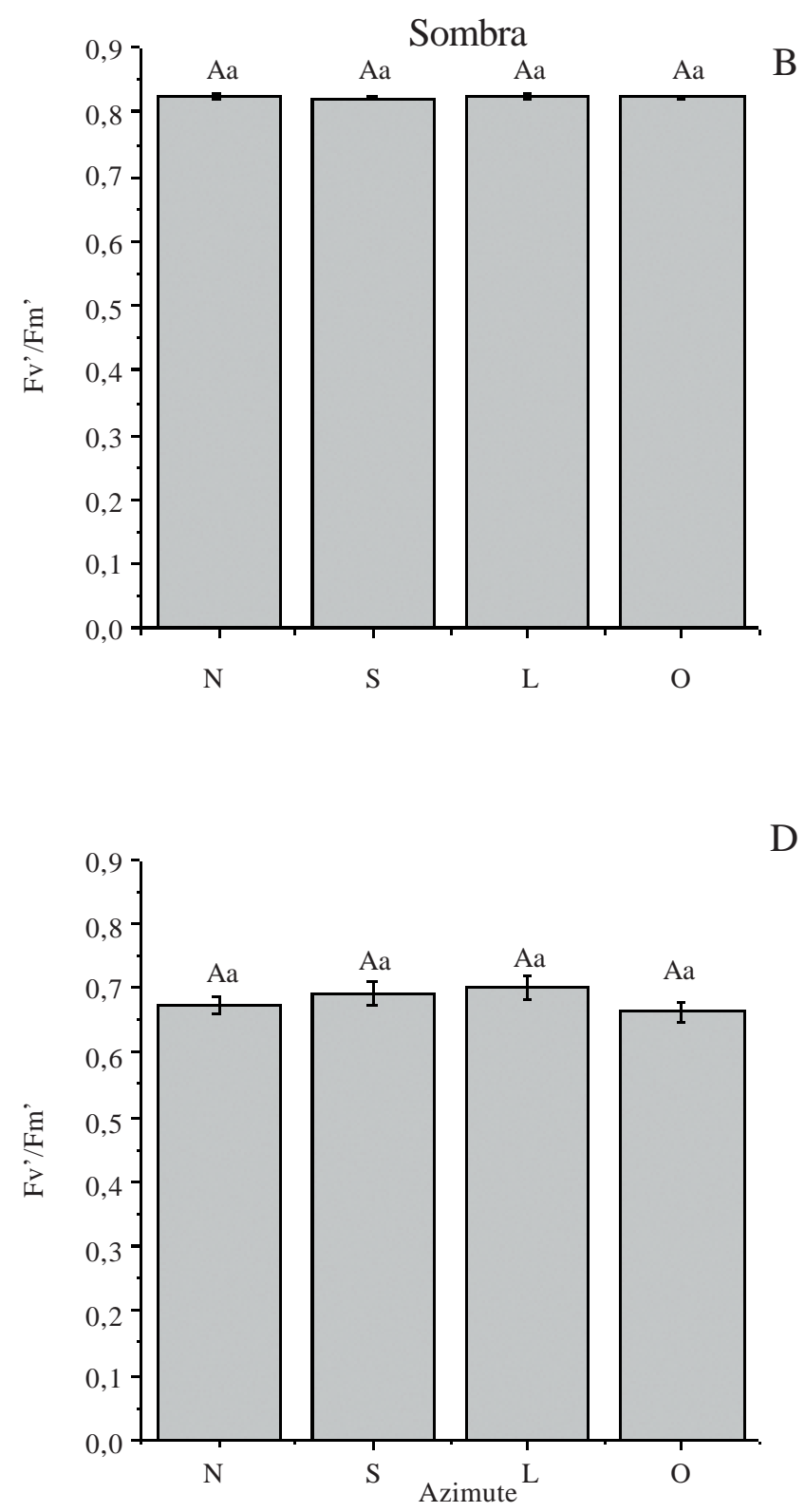

Figura 2.Valores da eficiência quântica potencial do FSII (Fv/Fm) no sol (A) e na sombra (B), eficiência quântica da antena (Fv'/Fm') no sol (C) e na sombra (D) de plantas de Cordia superba Cham. medidas no período das 11:00 h às 14:00 h. As letras maiúsculas diferentes sobre as colunas indicam diferenças estatísticas $(\mathrm{p}<0,05)$ de cada azimute entre os dois ambientes, e letras minúsculas diferentes representam diferenças estatísticas $(\mathrm{p}<0,05)$ entre os azimutes em cada ambiente. 
A taxa de transporte de elétrons foi significativamente $(\mathrm{p}<0,05)$ maior nas folhas de sol do que nas de sombra. Dentro de cada ambiente, não houve diferença $(p>0,05)$ entre os azimutes (Fig. 3A-B).

A eficiência quântica efetiva do FSII (ФPSII) foi significativamente $(\mathrm{p}<0,05)$ maior na sombra do que no sol. Com relação aos azimutes em cada ambiente, não foram detectadas diferenças estatísticas $(p>0,05)$ na sombra; no sol, as folhas no azimute oeste mostraram a maior ФPSII, enquanto no azimute sul foram observados os menores valores de ФPSII. A ФPSII nos azimutes norte e leste foram similares tanto ao azimute sul quanto ao azimute oeste (Fig. 3C-D).

O quenching fotoquímico (qP) foi maior ( $\mathrm{p}<0,05)$, em média, na sombra do que no sol, ocorrendo diferença significativa nos azimutes leste e sul do sol comparado aos mesmos azimutes no ambiente sombreado. Não houve diferença $(p>0,05)$ entre os azimutes dentro de cada ambiente (Fig. 4A-B).

Comparando os ambientes de sol e sombra, o quenching não fotoquímico (qNP) foi significativamente $(\mathrm{p}<0,05)$ maior no sol; o qNP medido nos diferentes azimutes nas folhas de sol foram diferentes entre si, sendo os valores medidos no azimute norte os maiores entre eles, enquanto no azimute oeste foram detectados os menores valores de qNP (Fig. 4C-D).

$\mathrm{Na}$ análise de arquitetura das plântulas foram detectadas diferenças estatísticas $(p<0,05)$ entre o ambiente de sol e de sombra nos parâmetros ângulo foliar, teor de clorofila, diâmetro do caule, número de folhas e comprimento médio dos ramos (Tab. 1). Por outro lado, os parâmetros como altura das plantas, índice de área foliar (IAF), área foliar total, número total de ramos, distância média entre folhas e peso específico (PE) não tiveram diferenças significativas $(\mathrm{p}>0,05)$ quando comparados entre os dois ambientes.

Todavia, algumas tendências podem ser destacadas que indicam as variações esperadas entre plantas de sol e de sombra. Em relação ao ângulo foliar, a média das plantas de sol $\left(90,4^{\circ}\right)$ foi $24 \%$ maior em relação às plantas de sombra $\left(72,7^{\circ}\right)$. O teor de clorofila das plantas de sombra teve valores 2,5 vezes maiores que as plantas de sol. Nas plantas de sol o número de ramos foi duas vezes maior que as plantas de sombra. Comparado com as plantas de sombra o diâmetro do caule das plantas de sol foi $46 \%$ maior. O número de folhas das plantas de sol foi duas vezes maior que as plantas de sombra, o comprimento dos ramos das plantas de sol foi $45 \%$ maior que as plantas de sombra, e a distancia média entre as folhas das plantas de sombra foi $22 \%$ maior que as plantas de sol. O IAF foi $67 \%$ maior nas plantas de sol em relação às plantas de sombra, e as plantas de sol tiveram um peso especifico $24 \%$ maior que as plantas de sombra.
A análise da estabilidade do desenvolvimento das plântulas por meio da análise de simetria foliar revelou diferenças consideráveis entre os dois ambientes. $\mathrm{Na}$ sombra, o desvio das médias de simetria foi maior do que no ambiente ensolarado. Em cada medida de desvio de simetria considerada na folha, os desvios foram maiores nas porções média e apical, e menor na porção basal, sem levar em consideração o ambiente em que se encontram. A análise considerando os desvios de simetria nas diferentes partes das folhas em cada ambiente mostrou que os valores de desvio da porção apical e mediana no ambiente de sol foram menores $(\mathrm{p}<0,05)$ do que na sombra, e na porção basal foram detectadas diferenças significativas $(\mathrm{p}<0,05)$ em ambos os ambientes. Considerando as diferenças entre os desvios nas diferentes partes da folha de cada ambiente, não houve diferenças significativas ( $p>0,05)$ entre os valores das porções apical, mediana e basal no ambiente ensolarado, diferente do que ocorreu no ambiente sombreado, onde a porção basal teve uma média significantemente menor $(\mathrm{p}<0,05)$ do que as outras porções dentro deste mesmo ambiente (Tab. 2).

\section{Discussão}

Segundo Anderson (1986), plantas de sombra mostram uma relação $3: 1$ dos centros de reação do fotossistema II para o fotossistema I, em comparação com a razão 2:1 encontrada em plantas de sol. Outras plantas de sombra, em vez de alterar a razão de FSI para FSII, adicionam mais clorofila às antenas do FSII. Essa adaptação parece aumentar a absorção de luz e a transferência de energia em ambientes sombrios, onde a luz vermelho-distante é mais abundante (Taiz \& Zeiger 2004). Da mesma forma, nossos resultados mostraram haver uma correlação linear positiva $(p<0,01)$ entre $o$ aumento do teor de clorofila e o aumento dos valores de eficiência da antena e eficiência quântica efetiva do FSII entre as plantas de sol e sombra (Fig. 5).

O acúmulo de clorofila total nas folhas sombreadas está relacionado com a pequena quantidade de luz disponível neste ambiente, já que absorção deste recurso depende da concentração de pigmentos fotossintéticos (Larcher 2004) e, de fato, em nosso estudo as plantas de $C$. superba crescidas em ambiente com apenas cerca de $10 \%$ de irradiância apresentaram concentrações de clorofila 2,5 vezes mais altas do que as plantas crescidas em ambiente de pleno sol. Os resultados são semelhantes aos citados na literatura (Boardman 1977; Ellsworth \& Reich 1992; Mendes et al. 2001), suportando as evidências de que as folhas cultivadas sob baixas intensidades de radiação apresentam teores mais altos de clorofila. 
O aparato fotossintético da planta é capaz de chegar a uma ótima eficiência em relação à absorção e a utilização de fótons. Entretanto, a forte radiação se torna um fator estressante na utilização dessa energia na fotossíntese sobrecarregando os processos fotossintéticos, resultando em uma baixa utilização quântica e, conseqüentemente, em um baixo rendimento assimilatório (fotoinibição) (Long et al. 1994). Os menores valores de Fv/Fm observados nas folhas de $C$. superba crescidas sob pleno sol (Fig. 2) indicaram a ocorrência de fotoinibição (Critchley 1998). Por outro lado, as folhas no ambiente sombreado mostraram altos valores de $\mathrm{Fv} / \mathrm{Fm}$, bem como alta eficiência da antena (Fv'/Fm'), o que é uma característica desejável em um ambiente com baixa disponibilidade de luz. Além disso, apenas no ambiente sombreado foi possível observar uma correlação positiva $(\mathrm{p}<0,05)$ entre os valores de Fv'/Fm' e da eficiência quântica efetiva do FSII (FApesar da fotoinibição

\section{Sol}

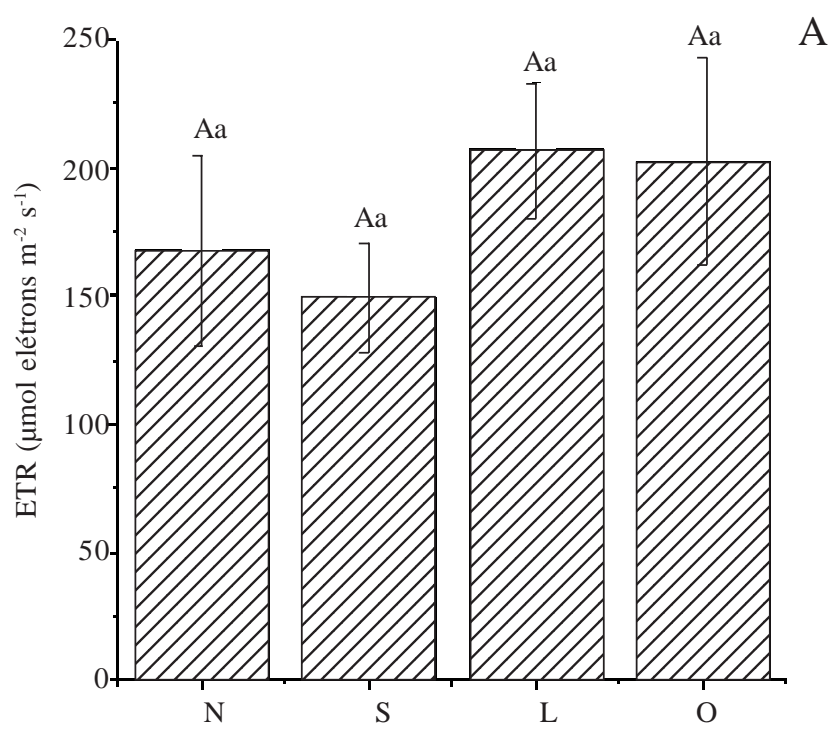

C

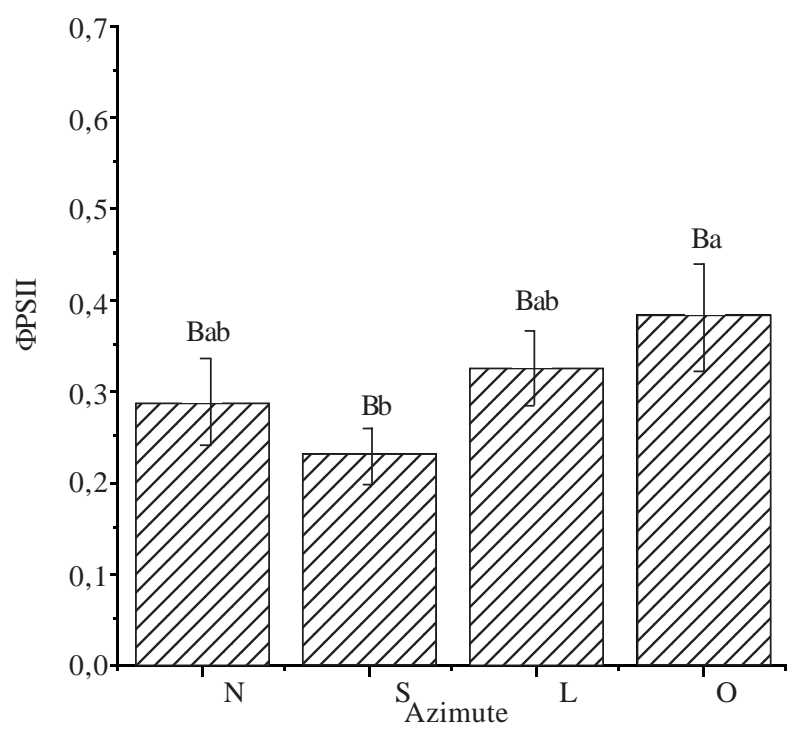

\section{Sombra}

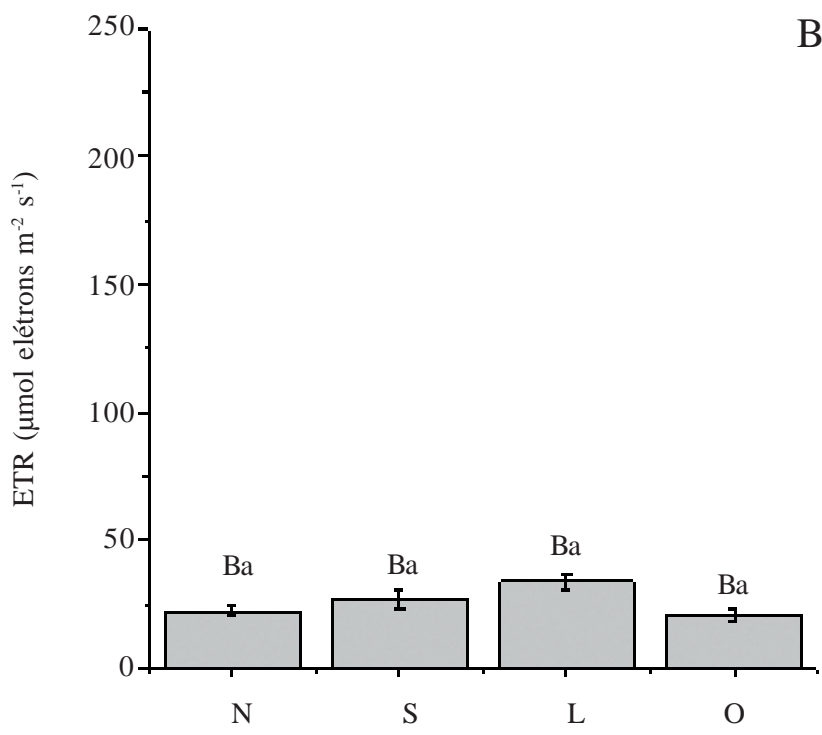

D

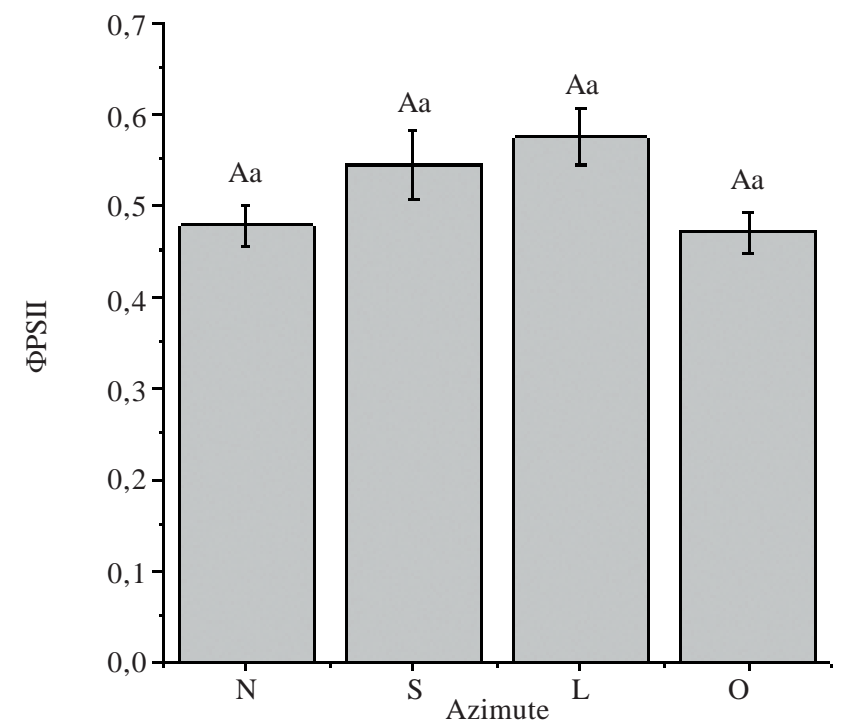

Figura 3. Taxa de transporte de elétrons (ETR) no sol (A) e na sombra (B), eficiência quântica do FSII (ФPSII) no sol (C) e na sombra (D) de plantas de Cordia superba Cham. medidas no período das 11:00 h às 14:00 h. As letras maiúsculas diferentes sobre as colunas indicam diferenças estatísticas $(\mathrm{p}<0,05)$ de cada azimute entre os dois ambientes, e letras minúsculas diferentes representam diferenças estatísticas (p < 0,05) entre os azimutes em cada ambiente. 
observada nas plantas de sol, a taxa de transporte de elétrons (ETR) foi maior do que nas plantas de sombra, como também observado por Ribeiro et al. (2004), que observaram que a ETR sofre maiores limitações em espécies secundárias do que em espécies pioneiras, como no caso de $C$. superba. Segundo os mesmos autores, a ETR aumenta proporcionalmente com a DFFF, uma vez que há uma maior disponibilidade de energia de excitação dos fotossistemas (Björkman \& Demmig-Adams 1994). Também em relação à DFFF, os valores de qP diminuem quando a DFFF aumenta (Ribeiro et al. 2004), o que explica os maiores valores deste parâmetro nos indivíduos do ambiente sombreado (Fig. 4). Em contrapartida, os valores de qNP foram maiores no sol. Isto é compreensível, uma vez que este parâmetro indica a quantidade de energia excessiva dissipada. A eficiência

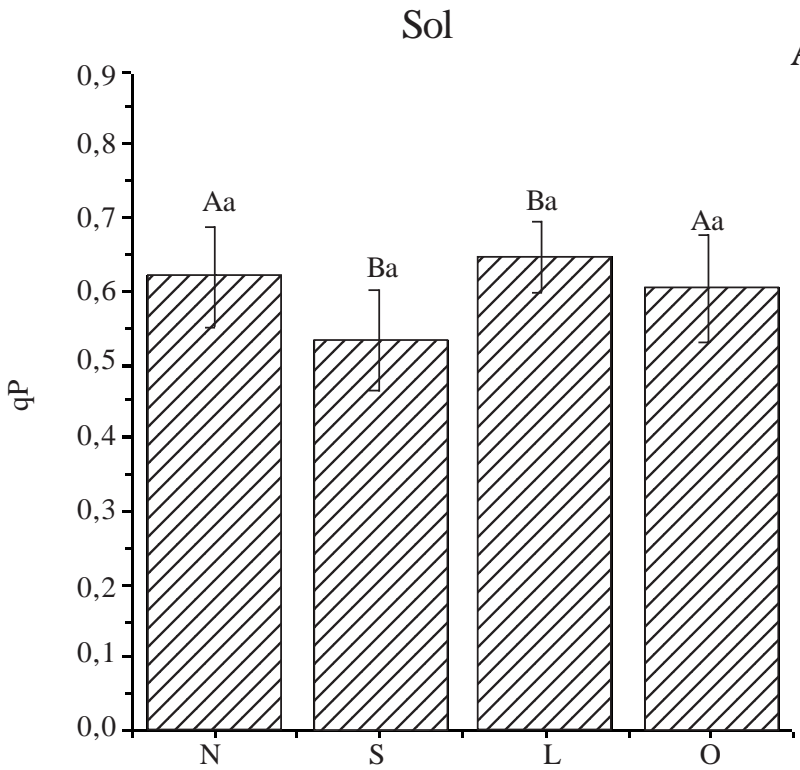

A

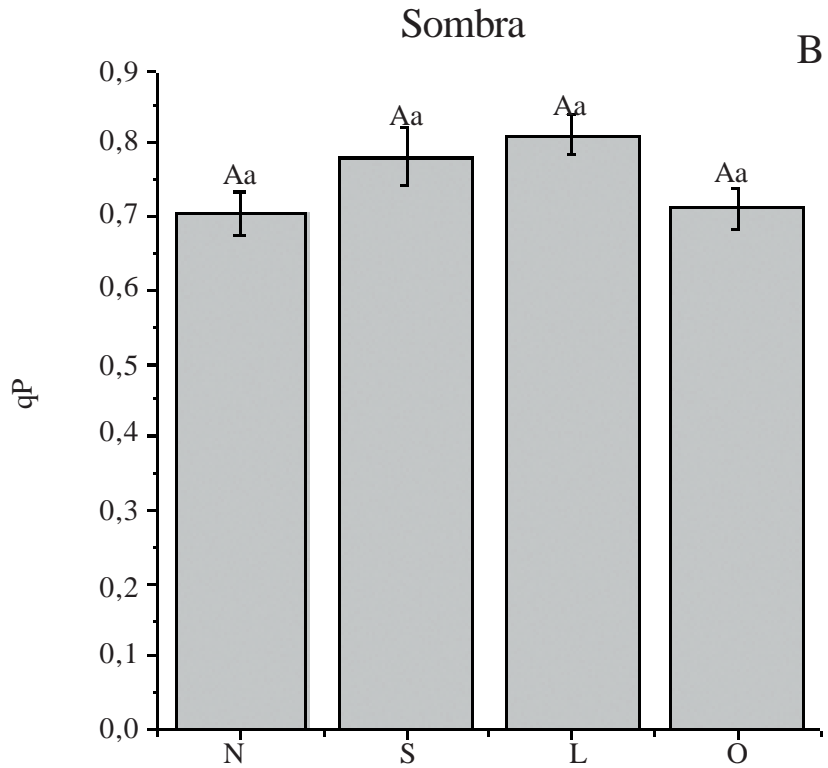

C
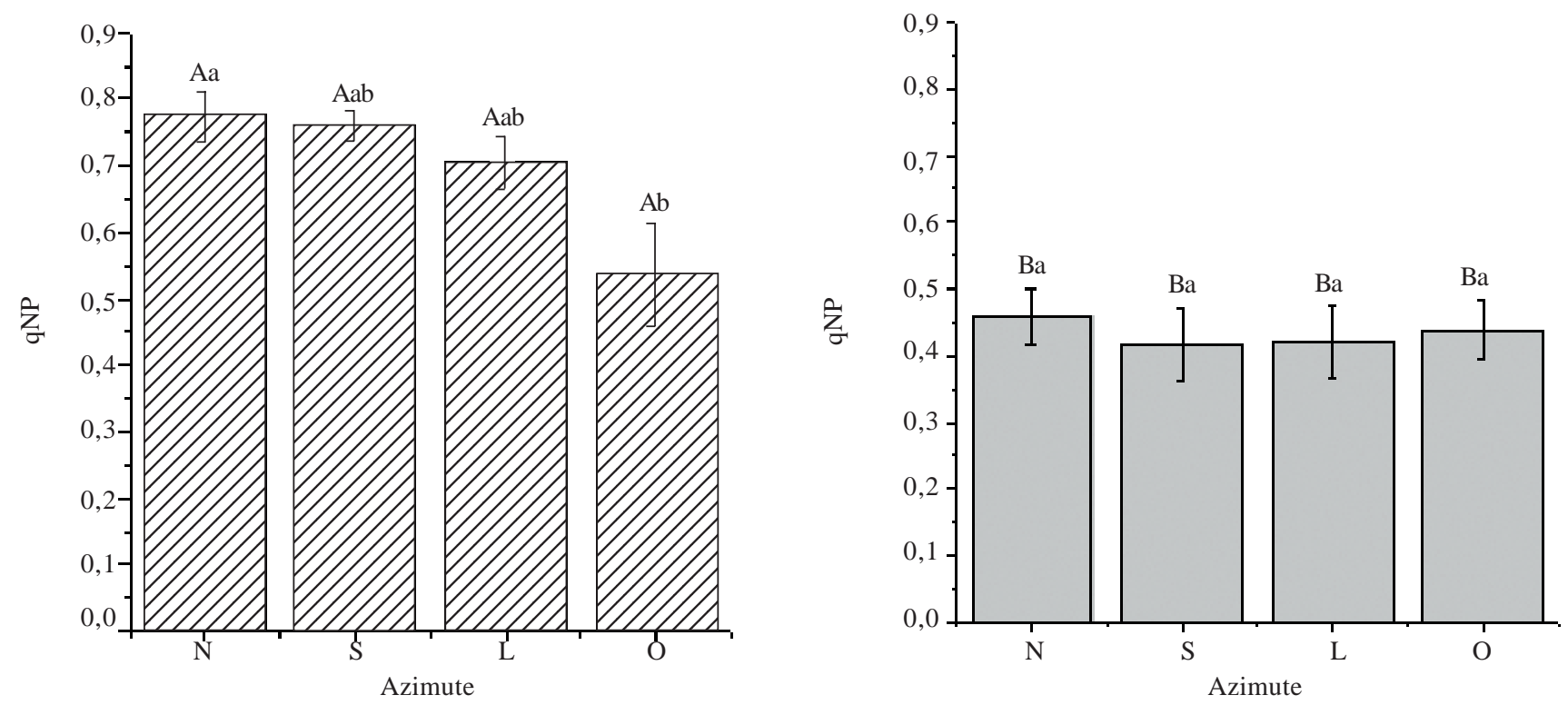

Figura 4. Quenching fotoquímico (qP) no sol (A) e na sombra (B), quenching não fotoquímico (qNP) no sol (C) e na sombra (D) de plantas de Cordia superba Cham. medidas no período das 11:00 h às 14:00 h. As letras maiúsculas diferentes sobre as colunas indicam diferenças estatísticas $(\mathrm{p}<0,05)$ de cada azimute entre os dois ambientes, e letras minúsculas diferentes representam diferenças estatísticas ( $<$ < 0,05) entre os azimutes em cada ambiente. 
Tabela 1. Parâmetros morfológicos (média e desvio padrão): ângulo foliar (ANG), teor de clorofila (CLOR), número de ramos (NR), diâmetro do caule (DC, mm), altura da planta (ALT, m), número de folhas (NF), comprimento médio de ramos (CR, cm), distância média entre as folhas (DF, $\mathrm{cm}$ ), área foliar total (AF, $\mathrm{m}^{2}$ ), índice de área foliar (IAF) e peso específico (PE, $\mathrm{g} \mathrm{cm}^{-2}$ ) de plantas de Cordia superba Cham. crescidas sob plano sol e sombreamento artificial. CV\% = coeficiente de variação, *indicam os parâmetros cujas médias foram significativamente diferentes $(\mathrm{p}<0,05)$ entre cada ambiente.

\begin{tabular}{|c|c|c|c|c|c|c|c|c|c|c|c|}
\hline Local & *ANG & *CLOR & NR & $* \mathrm{DC}$ & ALT & $* \mathrm{NF}$ & $* \mathrm{CR}$ & DF & $\mathrm{AF}$ & IAF & $\mathrm{PE}$ \\
\hline Sol $\mathrm{CV} \%$ & $\begin{array}{c}90,4 \pm 9,7 \\
10,749\end{array}$ & $\begin{array}{c}20,2 \pm 3,1 \\
15,333\end{array}$ & $\begin{array}{c}11,7 \pm 4,2 \\
35,687\end{array}$ & $\begin{array}{c}29,1 \pm 4,9 \\
17,020\end{array}$ & $\begin{array}{c}1,48 \pm 0,21 \\
14,450\end{array}$ & $\begin{array}{c}141,0 \pm 44,9 \\
31,818\end{array}$ & $\begin{array}{c}36,4 \pm 8,5 \\
23,359\end{array}$ & $\begin{array}{c}2,7 \pm 0,9 \\
35,153\end{array}$ & $\begin{array}{l}8,3 \pm 2,7 \\
32,640\end{array}$ & $\begin{array}{c}1,4 \pm 0,2 \\
12,259\end{array}$ & $\begin{array}{c}5,5 \pm 0,6 \\
11,604\end{array}$ \\
\hline $\begin{array}{l}\text { Sombra } \\
\text { CV\% }\end{array}$ & $\begin{array}{c}72,7 \pm 8,2 \\
11,236\end{array}$ & $\begin{array}{c}53,9 \pm 3,6 \\
6,715\end{array}$ & $\begin{array}{c}5,5 \pm 2,6 \\
48,105\end{array}$ & $\begin{array}{c}19,9 \pm 1,1 \\
5,347\end{array}$ & $\begin{array}{c}1,47 \pm 0,32 \\
21,953\end{array}$ & $\begin{array}{c}76,7 \pm 30,1 \\
39,223\end{array}$ & $\begin{array}{c}25,1 \pm 7,4 \\
29,641\end{array}$ & $\begin{array}{c}3,4 \pm 0,3 \\
10,595\end{array}$ & $\begin{array}{l}7,8 \pm 3,0 \\
38,400\end{array}$ & $\begin{array}{c}0,9 \pm 0,5 \\
63,816\end{array}$ & $\begin{array}{c}4,4 \pm 0,5 \\
10,823\end{array}$ \\
\hline
\end{tabular}

Tabela 2. Diferenças entre os desvios de simetria nas diferentes partes de folhas de Cordia superba Cham. crescidas em ambiente de sol e sombra. A e B representam diferenças significativas $(\mathrm{p}<0,1)$ entre os dois ambientes e a e b as diferenças $(\mathrm{p}<0,1)$ entre as três porções da folha em cada ambiente.

\begin{tabular}{lccc}
\hline & Ápice & Meio & Base \\
\hline Sol & $0,18^{\mathrm{Ba}}$ & $0,18^{\mathrm{Ba}}$ & $0,16^{\mathrm{Aa}}$ \\
Sombra & $0,25^{\mathrm{Aa}}$ & $0,26^{\mathrm{Aa}}$ & $0,18^{\mathrm{Ab}}$ \\
\hline
\end{tabular}

dessa dissipação é maior em espécies pioneiras e secundárias iniciais do que em espécies de sub-bosque (Ribeiro et al. 2004). Bilger et al. (1995) e Schreiber et al. (1994) também demonstraram que há uma relação linear entre o qNP e o excesso de DFFF. A dissipação da energia excessiva é essencial para a sobrevivência da planta, uma vez que previne danos causados pelo excesso dessa energia, evitando principalmente o estresse oxidativo. Os altos valores de qNP, em conjunto com altos valores do ETR, contribuem para uma maior remoção da energia excessiva absorvida pela clorofila

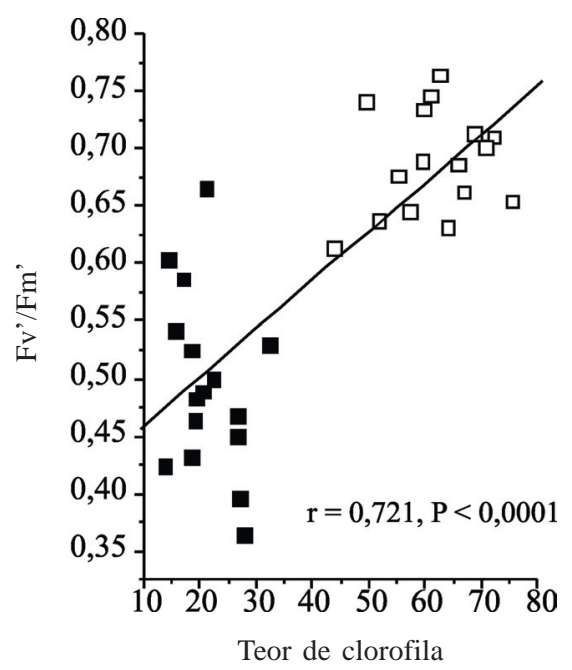

(Demmig-Adams \& Adams III 1992).

O ângulo das folhas em relação ao plano horizontal possui um importante papel tanto para evitar o excesso de radiação (Larcher 2004) como para otimizar a captura de luz (Werner et al. 2001). No presente estudo, os resultados obtidos a partir da análise dos dados mostraram diferenças entre os ângulos das folhas nos diferentes ambientes. No ambiente de sol, as plantas mostraram um posicionamento mais paralelo em relação ao solo, enquanto na sombra as folhas se posicionavam de forma mais inclinada $\left(70^{\circ}\right)$. Nossos resultados mostraram que houve uma correlação linear negativa $(\mathrm{p}<0,001)$ entre os ângulos das folhas e as eficiências quânticas efetiva e potencial do FSII, enquanto que os valores de qNP aumentaram com o aumento do ângulo foliar (Fig. 7), demonstrando que a posição da folha em relação ao plano horizontal de fato influencia a utilização fotossintética da luz. Assim, a inclinação das folhas de sombra está correlacionada com a maior eficiência do FSII no horário em que os raios solares incidem perpendicularmente ao plano horizontal, quando as medidas de fluorescência foram realizadas neste estudo.

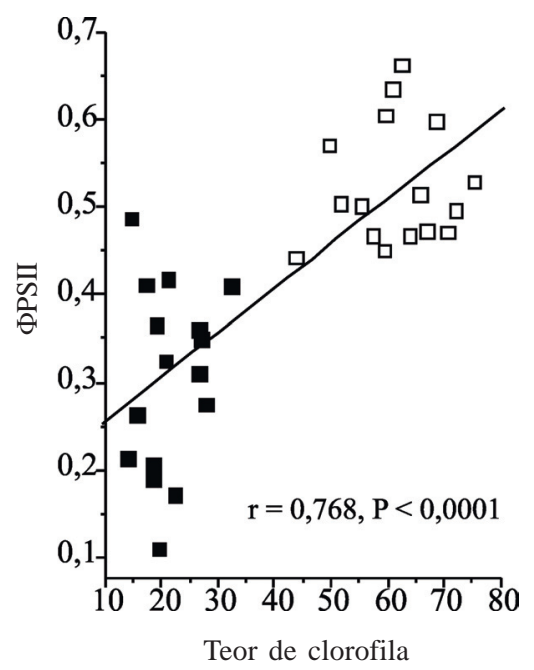

Figura 5. Análise de correlação entre os valores de Fv'/Fm' (eficiência da antena do FSII), ФPSII (eficiência quântica efetiva do FSII) e teor de clorofila (CCM, unidade óptica) medidos nas plantas de Cordia superba Cham. crescidas sob pleno sol e sombreamento $(\mathrm{n}=24)$. $\mathbf{\square}=$ sol; $\square=$ sombra. 
A direção das folhas em relação aos azimutes, em conjunto com a perpendicularidade em relação ao sol, determina uma maior absorção de $\mathrm{CO}_{2}$ (Werner et al. 2001), aumentando também a quantidade de biomassa produzida. Considerando a relação entre os azimutes

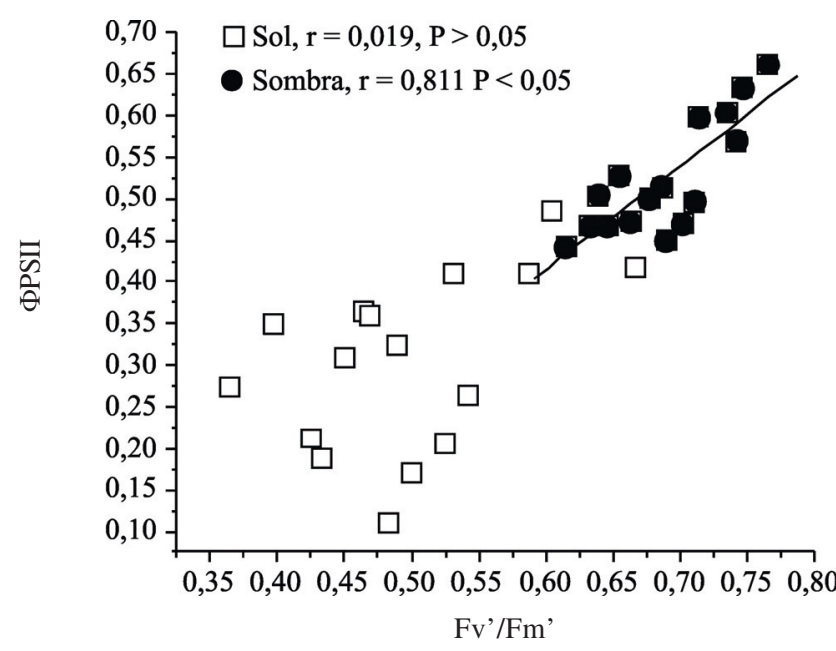

Figura 6. Análise de correlação entre os valores de Fv'/Fm' (eficiência da antenas do FSII) e ФPSII (eficiência quântica efetiva do FSII) medidos nas plantas de Cordia superba Cham. crescidas sob pleno sol e sombreamento $(\mathrm{n}=24)$.

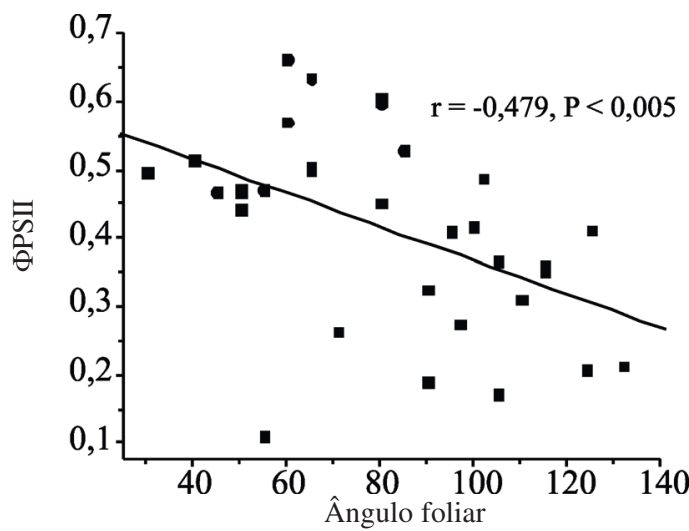

das folhas e a eficiência fotoquímica das plantas podese observar que nas plantas crescidas na sombra não foram detectadas nenhuma diferença significativa nos parâmetros de fluorescência da clorofila e a posição das folhas (Fig. 2B), fato que é razoável, uma vez que a luz em ambientes sombreados, especialmente sob sombreamento artificial, é difusa, de maneira que os fótons estão homogeneamente distribuídos no espaço atingindo as folhas de forma similar independentemente dos azimutes foliares. Por outro lado, nas plantas crescidas sob pleno sol, apesar de ainda não apresentarem uma copa densa, os valores de Fv'/Fm' e de ФPSII (Fig. 2C, 3C) tenderam a ser maiores no azimute oeste, o qual recebe uma menor carga radiativa durante o dia.

Os parâmetros de crescimento (Tab. 1) mostraram que o sombreamento afetou o acúmulo de biomassa que, em geral, foi maior no ambiente de sol (Ramos et al. 2003), pois a disponibilidade de energia fotossintética é alta e essa energia radiante é absorvida e transformada em fotossintatos que proporcionam desenvolvimento mais rápido da planta. Enquanto que nas plantas de sombra a distância entre as folhas foi maior, sendo uma maneira da planta evitar o auto-sombreamento aproveitando melhor a luz, nas plantas de sol houve uma
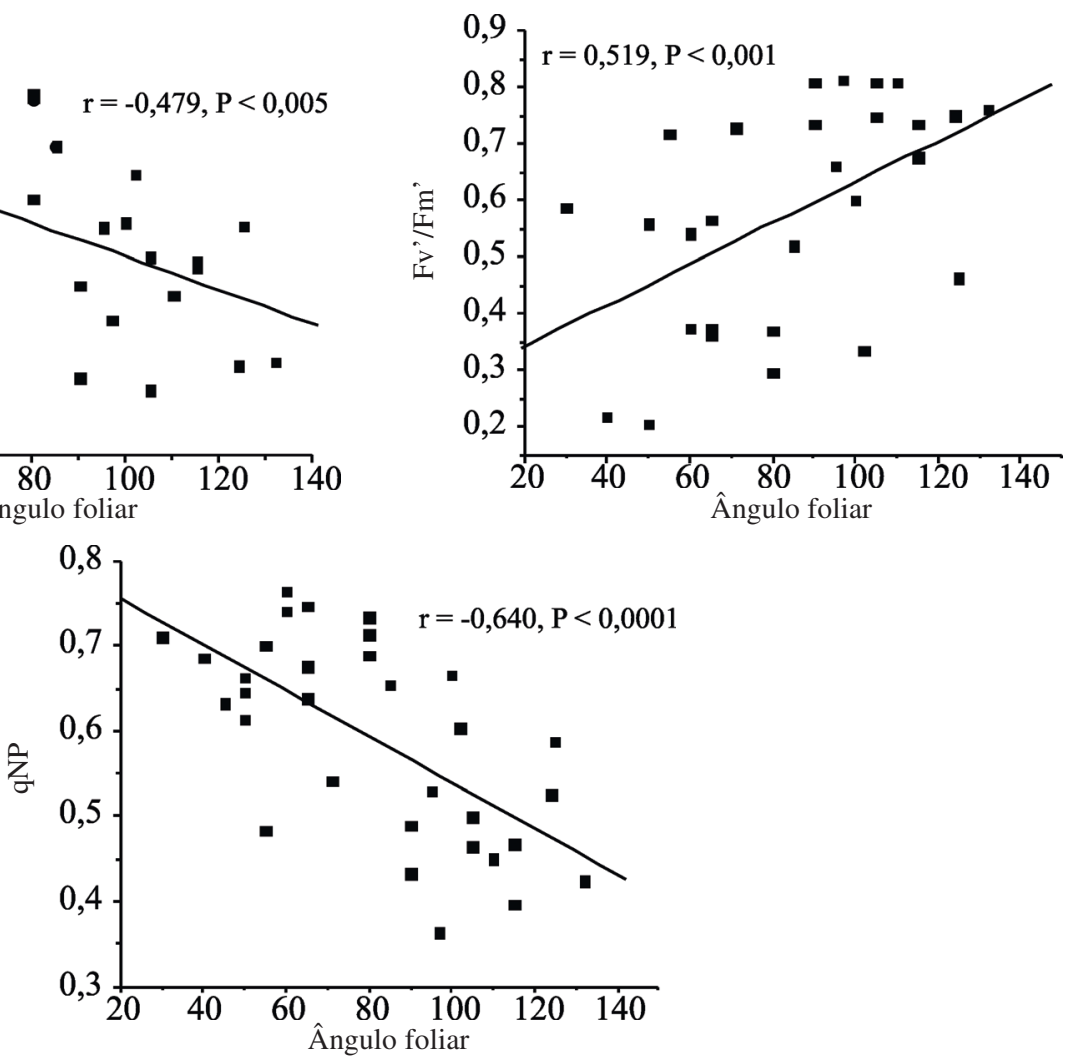

Figura 7. Análise de correlação entre o ângulo foliar e os valores de qNP (quenching não-fotoquímico), Fv/Fm (eficiência quântica potencial do FSII) e ФPSII (eficiência quântica efetiva do FSII) medidos nas plantas de Cordia superba Cham. crescidas sob pleno sol e sombreamento $(\mathrm{n}=24)$. 
tendência de apresentarem maior índice de área foliar, gerando maior auto-sombreamento e reduzindo a irradiância incidente excessiva (Larcher 2004).

De forma geral, os resultados relacionados à utilização da luz e a forma de crescimento das plantas nos dois ambientes evidenciaram diferentes estratégias de desenvolvimento, demonstrando a capacidade da espécie $C$. superba em se aclimatar a ambientes luminosos contrastantes. Isto indica o potencial de plasticidade fenotípica desta espécie, entendida aqui como a capacidade e um dado genótipo produzir diferentes fenótipos sob diferentes condições ambientais (Bradshaw 1965; Valladares et al. 2007).

Apesar desta plasticidade demonstrada pela espécie C. superba, os resultados de estabilidade do desenvolvimento indicaram que os dois ambientes não oferecem as mesmas condições favoráveis para o desenvolvimento desta espécie. Os resultados evidenciaram que as folhas crescidas em ambiente sombreado foram menos simétricas e, portanto, tiveram um desenvolvimento menos estável (Freeman et al. 1993). Essa instabilidade pode ser decorrente de limitações ambientais, no caso específico a falta de luz, fator decisivo para esta espécie, que é pioneira. Por outro lado, as plantas crescidas sob pleno sol não apresentaram desvios de simetria consideráveis, mostrando que seu desenvolvimento foi mais estável (Freeman et al. 1993). $\mathrm{O}$ tipo de assimetria encontrado na sombra foi a assimetria flutuante, ou seja, os desvios foram aleatórios, e não direcionais (Palmer \& Strobeck 1986; Møller \& Swaddle 1997), uma vez que o teste comparativo entre as medidas do lado esquerdo e direito da folha não detectaram a ocorrência de assimetria direcional, conforme descrito no item Materiais e Métodos. A simetria, mais especificamente a assimetria flutuante, é amplamente usada em estudos sobre instabilidade do desenvolvimento (Graham et al. 1993). Isso acontece porque ela é resultado de processos internos do indivíduo, como fisiologia e metabolismo, além de também ser programada pelo material genético. Portanto, a simetria revela, num nível individual, aspectos da qualidade genética e fenotípica do organismo (Møller \& Swaddlle 1997).

A primeira hipótese considerada neste estudo não foi suportada, como demonstrado pelos resultados da análise de simetria foliar, que revelaram que as plantas crescidas em ambiente ensolarado tinham folhas mais simétricas, ao contrário das plantas de sombra, cujas folhas apresentavam uma significativa assimetria flutuante. Isto sugere que, apesar do ambiente de pleno sol possuir uma maior heterogeneidade ambiental do que ambientes sombreados (Chazdon et al. 1996), o status de espécie pioneira de $C$. superba parece ser uma característica adaptativa suficientemente desenvolvida para permitir a formação de um fenótipo estável em uma ambiente variável.

Por outro lado, a hipótese sobre a capacidade da espécie Cordia sperba em desenvolver diferentes estratégias de utilização de luz foi satisfatoriamente corroborada, uma vez que nossos resultados indicaram que esta espécie possui a capacidade de desenvolver diferentes fenótipos em resposta a disponibilidades de luz contrastantes. Todavia, embora os indivíduos crescidos em ambiente sombreado terem apresentado uma grande plasticidade fenotípica mostrando características típicas de plantas de sombra, comportamento que sugere que esta espécie poderia ser considerada uma secundária inicial mais do que uma espécie tipicamente pioneira, isto não foi suficiente para a manutenção de um desenvolvimento estável sob baixa irradiância.

\section{Agradecimentos}

Este trabalho contou com auxílio financeiro da FAPESP (proc. 03/06939-5) e do CNPq (bolsa produtividade para o autor G.M. Souza).

\section{Referências bibliográficas}

Anderson, J.M. 1986. Photoregulation of the composition, function, and structure of thylakoid membranes. Annual Review of Plant Physiology 37: 93-136.

Barnes, P.W.; Beychlag, W.; Ryel, R.J.; Flint S.D. \& Caldwell, M.M. 1990. Plant competition for light analyzed whith a multispecies canopy model. III. Influence of canopy structure in mixtures and monocultures of wheat and wild oat. Oecologia 82: 560-566.

Bilguer, W.; Schreiber, U. \& Bock, M. 1995. Determination of the quantum efficiency of photosystem II and non-photochemical quenching of chlorophyll fluorescence in the field. Oecologia 102: $425-432$.

Björkman, O. \& Demmig-Adams, B. 1994. Regulation of photosynthetic light energy capture, conversion and dissipation in leaves of higher plants. Pp. 17-47. In: E.D. Schulze \& M.M. Caldwell (eds.). Ecophysiology of photosynthesis. New York, Springer.

Boardman, N.K. Comparative photosynthesis of sun and shade plants. 1977. Annual Review of Plant Physiology 28: 355-377.

Bradshaw A.D. 1965. Evolutionary significance of phenotypic plasticity in plants. Advances in Genetics 13: 115-155.

Chazdon, R.L.; Pearcy, R.W.; Lee, D.W. \& Fetcher, N. 1996. Photosynthetic responses of tropical forest plants to contrasting light environments. P. 643. In: S.S. Mulkey.; R.L. Chazdon. \& A.P. Smith. Tropical forest plant ecophysiology. New York, Chapman \& Hall.

Critchley, C. 1998. Photoinhibition. Pp. 264-272. In: A.S. Raghavendra (ed.). Photosynthesis, a comprehensive treatise. Cambridge, Cambridge University Press.

Demming-Adams, B. \& Adams III, W.W. 1992. Photoprotection and other responses of plants to high light stress. Annual Review of Plant Physiology and Plant molecular Biology 43: 599-626.

Duncan, W.G. 1971. Leaf angles, leaf area and canopy photosynthesis. Crop Science 11: 482-485. 
Ellsworth, D.S. \& Reich, P.B. 1992. Leaf mass per area, nitrogen content and photosynthetic carbon gain in Acer saccharum seedlings in contrasting forest light environments. Functional Ecology 6: 423-435.

Forseth, I.N. \& Norman, J.M. 1993. Modeling of solar irradiance, leaf energy budget, and canopy photosynthesis. Pp. 217-219. In: D.O. Hall.; J.M.O. Scurlock.; R.C. Nordenkampf.; R.C. Leegood \& S.P. Long (eds.). In: Techniques in Photosynthesis and Productivity Research for a Changing Environment. London, Chapman \& Hall.

Freeman, D.C.; Graham, J.H. \& Emlen, J.M. 1993. Developmental stability in plants: symmetries, stress and epigenesis. Genetica 89: $97-119$.

Graham, J.H.; Freeman, D.C. \& Emlen, J.M. 1993. Antisymmetry, directional asymmetry, and dynamic morphogenesis. Genetica 89: $121-137$.

Hirose, T. 2005. Development of the Monsi-Saeki theory on canopy Structure and Function. Annals of Botany 95: 483-494.

Lambers, H.; Chapin III, F.S. \& Pons, T.L. 1998. Plant physiological ecology. New York, Springer Verlag.

Larcher, W. 2004. Ecofisiologia vegetal. São Carlos, Rima.

Long, S.P.; Humphries, S. \& Falkowski, P.G. 1994. Photoinhibition of photosynthesis in nature. Annual Review of Plant Physiology and Plant Molecular Biology 45: 633-662.

Loomis, R.S. \& Willams, W.A. 1969. Productivity and the morphology of crop stands: pattern with leaves. Pp. 27-47. In: J.D. Eastin et al. Physiological aspects of crop yield. Am. Soc. of Agronomy.

Lorenzi, H. 1992. Árvores brasileiras: manual de identificação e cultivo de plantas arbóreas nativas do Brasil. Nova Odessa, Plantarum.

Machado, E.C.; Pereira, A.R.; Camargo, M.B.P. \& Fahl, J.I. 1985. Relação radiométricas de uma cultura de cana-de-açúcar. Bragantia 44: 229-238.

McCain, D.C.; Croxdale, J. \& Markley, J.L. 1988. Water is allocated differently to chloroplasts in sun and shade leaves. Plant Physiology 86: 16-18

Mendes, M.M.; Gazarini, L.C. \& Rodrigues, M.L. 2001. Acclimation of Myrtus communis to contrasting Mediterranean light environments-effects on structure and chemical composition of foliage and plant water relations. Environmental and Experimental Botany 45: 165-178.

Møller, A.P. \& Swaddle, J.P. 1997. Asymmetry, Developmental Stability, and Evolution. New York, Oxford University Press, Inc.

Monsi, M. \& Saeki, T. 1953. Über den Lichtfaktor in den Pflanzengesellschaften, seine Bedeutung für die Stoffproduktion. Japanese Journal of Botany 14: 22-52.

Norman, J.M. \& Campbell, G.S. 1989. Canopy structure. Pp. 301-325. In: R.W. Pearcy; J. Ehleringer; H.A. Mooney \& P.W. Rundel (eds.). Plant Physiological Ecology. Field Methods and Instrumentation. London, Chapman \& Hall.

Palmer, A.R. \& Strobeck, C. 1986. Fluctuating asymmetry: measurement, analysis, patterns. Annual Review of Ecology and Systematics 17: 391-421.
Pickett, S.T.A. \& Kempf, J.S. 1980. Branching patterns in forest shrubs and understory trees in relation to habitat. New Phytologist 86: 219-228.

Pinheiro, F.J.A. 1994. Anatomia foliar, desenvolvimento e interceptação da luz de cultivares de arroz (Oryza sativa L.). Dissertação de Mestrado. Goiânia, Universidade Federal de Goiás.

Ramos, K.M.O.; Felfili, J.M.; Fagg, C.W.; Silva, J.C.S. \& Franco, A.C. 2004. Desenvolvimento inicial e repartição de biomassa de Amburana cearensis (Allemão) A.C. Smith, em diferentes condições de sombreamento. Acta Botanica Brasilica 18: 351-358.

Ribeiro, R.V.; Souza, G.M.; Manzatto, A.G.; Machado, E.C. \& Oliveira, R.F. 2004. Chlorophyll fluorescence of tropical tree species in a semi-decidous Forest gap. Revista Árvore 28: 21-27.

Ribeiro, R.V.; Souza, G.M.; Oliveira, R.F. \& Machado, E.C. 2005. Photosynthetic responses of tropical tree species from different successional groups under contrasting irradiance conditions. Revista Brasileira de Botânica 28: 149-161.

Schreiber, U.; Bilger, W. \& Neubauer, C. 1994. Chlorophyll fluorescence as a non-intrusive indicator for rapid assessment of in vivo photosynthesis. Pp. 49-70. In: E.D. Schulze \& M.M. Caldwell (eds.). Ecophysiology of photosynthesis. New York, Springer Verlag: Berlin Heidelberg.

Setzer, J. 1966. Atlas Climático e Ecológico do Estado de São Paulo. Pp. 35-39. São Paulo, Ed. Comissão Interestadual da Bacia do Paraná-Uruguai em colaboração com as centrais elétricas de SP (CESP).

Souza, G.M. \& Oliveira R.F. 2004. Estabilidade e complexidade em sistemas biológicos. Pp. 123-134. In: G.M. Souza; I.M.L. D’Ottaviano \& M.E.Q. Gonzales (orgs.). Auto-Organização: estudos interdisciplinares. Coleção CLE, v.38. Campinas.

Souza, G.M.; Aidar, S.T. \& Oliveira, R.F. 2004. Developmental stability and network connectance in Phaseolus vulgaris L. genotypes under water deficit. Israel Journal of Plant Sciences 52: 205-212.

Souza, G.M.; Viana, J.O.F. \& Oliveira, R.F. 2005. Asymmetrical leaves induced by water deficit show asymmetric photosynthesis in common bean. Brazilian Journal of Plant Physiology 17:223-227.

Strauss-Debenedetti, S. \& Bazzaz, F.A. 1996. Photosynthetic characteristics of tropical trees along successional gradients. Pp. 162-186. In: S.S. Mulkey; R.L. Chazdon \& A.P. Smith (eds.). Tropical forest plant ecophysiology. New York, Chapman \& Hall.

Taiz, L. \& Zeiger, E. 2004. Fisiologia vegetal. 3 ${ }^{a}$ ed. Porto Alegre, Artmed.

Valladares, F.; Gianoli, E. \& Gómez, J.M. 2007. Ecological limits to plant phenotypic plasticity. New Phytologist 176: 749-763

Watson, D.J. 1947. Comparative physiological studies on the growth of field crops. I. Variation in net assimilation rate and leaf area between species and varieties, and within and between years. Annals of Botany 11: 41-76.

Werner, C.; Ryel, R.J.; Correia, O. \& Beyschlag, W. 2001b. Structural and functional variability within the canopy and its relevance for carbon gain and stress avoidance. Acta Oecologica 22: $129-138$ 